DR. VICTORIA GNAZZO (Orcid ID : 0000-0002-3381-5834)

Article type : Original Article

\title{
Mouse model as an efficacy test for foot-and-mouth disease vaccines
}

Gnazzo V, Quattrocchi V, Soria I, Pereyra E, Langellotti C, Pedemonte A, Lopez V, Marangunich L, Zamorano P.

Instituto Nacional de Tecnología Agropecuaria, Nicolas Repetto y Los Reseros, Buenos Aires, 1033,
Argentina. Argentina.

vgnazzo@anlis.gov.ar

Running head: Mouse model for efficacy test to FMDV vaccines

Competing interests: The authors declare no competing interests.

The data that support the findings of this study are available from the corresponding author upon reasonable request.

\section{ACKNOWLEDGEMENTS AND FUNDING SOURCES}

This work was supported by the Consejo Nacional de Investigaciones Científicas y Técnicas (CONICET) of Argentina, and FONCYT (PAE 37206- PID 74/2007). INTA, SENASA AND Biogénesis Bagó are members of the Inter-institutional FMD Research and Development Network (RIIDFA) of Argentina. 


\section{ABSTRACT}

Protection against foot-and-mouth disease virus (FMDV) has been linked to the development of a humoral response. In Argentina, the official control tests for assessing the potency of FMD vaccines are Protection against Podal Generalization (PPG) and Expected Percentage of Protection (EPP) curves built with quantitative data of antibodies determined by liquid-phase blocking ELISA (lpELISA). The results of these tests are used to accept or discard vaccines at the batch level. In this report, a mouse model was assessed as an alternative efficacy control for FMDV vaccines. To this aim, groups of cattle $(n=18)$ and BALB/c mice $(n=16)$ were inoculated with commercial FMDV vaccines and bleedings were performed 60 days post vaccination (dpv) in cattle and $21 \mathrm{dpv}$ in mice. Specific FMDV antibody titres were measured in both species by a standardized lpELISA. A statistically significant association between antibody levels in cattle and mice has already been demonstrated. However, some vaccines have been misclassified since they were considered protective based on lpELISA results but did not induce good protection in cattle upon challenge. For this reason, other immunological parameters were evaluated to improve the prediction of protection in mice, without the need of using infective virus. In addition, antibody titres by 1 EELISA, the IgG2b/IgG1 isotype ratio and the Avidity Index were identified as good predictors, resulting in an optimal predictive model of protection. This mouse model could be a simple and economic alternative for testing FMD vaccines since the disadvantages of high costs and facility requirements associated with the use of large animals are overcome.

Keywords: foot-and-mouth disease virus, vaccine, mouse model, protection prediction

This article is protected by copyright. All rights reserved 


\section{INTRODUCTION}

Foot-and-Mouth disease virus (FMDV) is a Picornavirus belonging to the Aphthovirus genus (Soria et al., 2017). FMDV has seven distinct serotypes, namely O, A, C, SAT1, SAT2, SAT3 and Asia 1. This virus produces foot-and-mouth disease (FMD), a devastating and highly transmissible infection of farm animals, with large associated economic losses.

Some countries are either FMD free or close to achieving eradication, while others are at an early stage of FMD control. In many countries, FMD control is performed by regular vaccination based on inactivated whole-virus (Soria et al., 2017).

Worldwide, potency testing of FMD vaccines is performed in the target species using either direct or indirect methods. The "Gold Standard" test is the in vivo viral challenge of primo-vaccinated animals. Protection against podal generalization (PPG) and $50 \%$ protective dose $\left(\mathrm{PD}_{50}\right)$ are direct methods commonly in use (OIE, 2009). The PPG method, currently used in Latin America, has proved to be highly reliable (Filho et al., 1993). In this test, vaccine potency is tested in a group of cattle in which 16 animals are vaccinated and 2 remain as unvaccinated controls. According to the World Organisation of Animal Health (OIE, 2009), a vaccine batch is approved for licensing if at least 12 out of the 16 vaccinated animals are protected after challenge (i.e., 75\% PPG). In Argentina, PPG has been partially replaced by the Expected Percentage of Protection (EPP) in which titres of antibodies (Abs) against FMDV in the sera of vaccinated cattle are determined by liquid phase ELISA (lpELISA). Since there is a correlation between Ab titres and protection, the probability of cattle to be protected against viral challenge after a single dose of vaccination is estimated by the titres of antiFMDV antibodies (Alonso et al., 1990). Nevertheless, viral challenge is still used for licensing vaccines, when new viral strains are included in vaccines or when required by veterinary services (Maradei et al., 2008).

Both methods, PPG and EPP, are expensive, logistically demanding, and require availability of FMDV-serologically negative cattle.

In general, high $\mathrm{Ab}$ titres in serum are considered a guarantee of adequate immunity and protection against the virus (Maradei et al.,2008; van Bekkum, 1969; Panaftosa, 1994). However, it is possible to find protected animals with low neutralizing Ab levels (Sobrino et al., 2001) or unprotected animals with high antibody titres, which suggests that protection could also be mediated by other components 
of the immune system. In this sense, Lavoria et al. (2012) proposed that, in cattle, the Avidity Index and the ratio of $\mathrm{Ab}$ isotypes against FMDV could serve to discriminate protected from unprotected cattle. On the other hand, Quattrocchi et al. (2011) reported the presence of non-neutralizing antibodies with opsonizing activity in protected animals that could suffice to confer protection at early post-vaccination times.

Due to the difficulties involved in using bovines, the mouse model has been widely used for FMD studies. Although the differences between mice and natural hosts in terms of infection and disease course are numerous, it has been possible to establish parallels between mice and cattle, with respect to virus replication (Borca et al., 1984; Berinstein et al., 1993; Fernández et al., 1986), presence of seroneutralizing Abs for long periods of time after infection (López et al., 1990), participation of macrophages in virus opsonization (Quattrocchi et al., 2011; 2014), differential immune response generated by infection and vaccination (Berinstein et al., 1991), and role of dendritic cells in the immune response to FMDV (Ostrowski et al., 2007; Langellotti et al., 2012).

For this reason, we have analysed the mouse model as a predictor of the protection induced by FMD vaccines and standardized some serological techniques in order to establish a statistically valid correlation with cattle. To this end, a possible correlation between lpELISA titers, IgG2b/IgG1 ratios and Avidity index in sera from vaccinated mice and protection of vaccinated cattle challenged with infectious FMDV O1 Campos strain was assessed.

This article is protected by copyright. All rights reserved 


\section{MATERIALS AND METHODS}

Ethics Statement

All experiments involving animals were carried out according to INTA Ethics Manual "Guide for the use and care of experimental animals". The protocol was approved by the Institutional Animal care and use Committee "CICUAE INTA CICVyA” (Permit number: 16/2011).

Mice

Two month-old male BALB/c mice, purchased from National University of La Plata (Buenos Aires, Argentina), were housed, four per cage, and kept at $20 \pm 2{ }^{\circ} \mathrm{C}$ under an automatic $12 \mathrm{~h}$ light-dark schedule.

Cattle

Hereford calves, serologically negative for FMDV, between 24 and 30 months of age and weighing 280-350 kg obtained from the Patagonia region of Argentina (recognized as free of FMD without vaccination by OIE), were used in the experiment.

Virus

The O1 Campos strain was selected for this study because it conforms to the antigen banks that are used in case of FMDV outbreaks around the world (Galdo Novo et al., 2018) and because it is one of the strains used for the PPG test in Argentina.

FMDV O1 Campos was kindly provided by Biogenesis Bagó S.A. as a binary ethylene-imine (BEI)inactivated virus suspension (iFMDV). Purified virus was obtained by a sucrose density gradient centrifugation method (Pega et al., 2013) and was used for the ELISA assay. For challenge and virus neutralization assays, infective virus (kindly donated by the Argentine National Service of Animal Health, SENASA) was used in BSL-4 OIE laboratories and boxes at INTA.

Vaccines

In order to establish the mouse model, experimental vaccines were formulated with increasing doses of $0.0125,0.025,0.05,0.1,0.5,1$ and $2 \mu \mathrm{g}$ of inactivated FMDV (iFMDV) O1 Campos per mouse. Monovalent FMDV O1 Campos vaccines were checked for sterility, safety, and purity according to SENASA Resolution $\left(\mathrm{N}^{\circ}\right.$ 609/2010). The commercial and experimental vaccines used in cattle and mice were formulated in companies that produce FMDV vaccines in Argentina.

This article is protected by copyright. All rights reserved 
Experimental and commercial FMDV vaccines formulated with O1 Campos FMDV strain as monovalent formulations $(n=6)$ or different commercial polyvalent vaccines $(n=39$, containing 4 FMDV strains: A/Argentina/ 2000, A/Argentina/2001, A24 Cruzeiro/Brazil/55 and O1 Campos) were used. Sixteen of these vaccines had been authorised by SENASA for viral challenge against FMDV O1 Campos strain in vaccinated cattle at $90 \mathrm{dpv}$.

Experimental design

Each polyvalent vaccine $(n=39)$ was evaluated in a group of 18 bovines, 2 of which were unvaccinated and 16 vaccinated using $2 \mathrm{~mL} /$ dose by the intramuscular or subcutaneous route, and in groups of 18 mice, 2 of which were unvaccinated and 16 vaccinated by the intraperitoneal (ip) route $(0.2 \mathrm{~mL})$. Exploratory bleedings were performed at $60 \mathrm{dpv}$ in cattle and at $21 \mathrm{dpv}$ in mice, and antibody responses were determined by lpELISA (Figure 1).

Sixteen FMDV vaccines were previously authorised by SENASA for PPG test, these vaccines were polyvalent (A/Argentina/ 2000, A/Argentina/2001, A24 Cruzeiro/Brazil/55 and O1 Campos). Groups of cattle and mice were challenged with FMDV O1 Campos infectious virus as described below.

Viral Challenge tests in cattle

Vaccine potency trials in cattle (PPG) were performed by SENASA according to their specific regulations (SENASA, 2017). Briefly, for each vaccine batch, 16 individually ear-tagged cattle, negative for FMDV antibodies, were vaccinated intramuscularly in the upper part of the neck with a full dose cattle vaccine $(2 \mathrm{~mL})$. Two unvaccinated control animals were included in each potency trial. Ninety dpv, all vaccinated and unvaccinated animals were challenged by intradermal inoculation of $10^{4}$ suckling mouse lethal dose 50\% (SMLD50) of challenge virus into four different sites on the upper surface of the tongue ( $0.25 \mathrm{ml}$ per site). Seven days post challenge (dpc), all animals were clinically checked for FMDV-induced foot lesions. PPG was calculated as the number of vaccinated protected animals (i.e., absence of FMDV-induced foot lesions) divided by the total number of vaccinated animals $\times 100$. The trial was considered valid if both unvaccinated control animals showed FMDV-induced lesions on at least one foot. The test was carried out in a high safety box in INTA. According to SENASA Resolution $\mathrm{N}^{\circ} 609 / 17$, a vaccine batch is approved for licensing if at least 12 out of the 16 vaccinated animals are found to be protected (75\% PPG). A

This article is protected by copyright. All rights reserved 
vaccine batch must be retested if 10-11 vaccinated cattle are protected against the challenge $(62.5 \%$ $68.8 \% \mathrm{PPG}$ ) and is rejected if 7 or more vaccinated animals show lesions on the feet.

Viral challenge test in mice

Protection against FMDV in the mouse model was defined by the presence or absence of viremia 24 $\mathrm{h}$ after infection as described by Quattrocchi et al. (2011), with modifications. Briefly, mice were ip inoculated at $21 \mathrm{dpv}$ with $10^{4.5} \mathrm{TCID}_{50}$ infectious O1 Campos FMDV strain. After $24 \mathrm{~h}$, animals were anesthetized and bled. The heparinized blood (100 $\mu 1 /$ well) was spread in 48 well-plates onto BHK21 cell monolayers and incubated for $40 \mathrm{~min}$ at $37^{\circ} \mathrm{C}$ in a $5 \% \mathrm{CO}_{2}$ atmosphere. Then, cell monolayers were washed three times with sterile PBS. Fresh DMEM supplemented with $2 \%$ fetal calf serum was added and the cells were incubated for $48 \mathrm{~h}$ at $37^{\circ} \mathrm{C}$ in a $5 \% \mathrm{CO}_{2}$ atmosphere. Animals were considered protected if the cell monolayer did not present cytopathic effects after one blind passage (no viremia detected). In every viral challenge assay, 2 mice inoculated with sterile PBS were included as positive infection controls. Percentages of protection were calculated as $100 \mathrm{x}$ (protected mice/challenged mice).

Serological assays

- Total FMDV specific antibodies in mice

An lpELISA test was used according to Hamblin et al. (1987), with modifications. Briefly, Immulon IIHB plates were coated overnight at $4{ }^{\circ} \mathrm{C}$ with rabbit $\alpha$-O1 Campos FMDV serum diluted to an optimal concentration in carbonate-bicarbonate buffer, $\mathrm{pH}$ 9.6. After washing with $0.05 \%$, Tween20/phosphate buffered saline (PBST) plates were blocked with PBST/1\% ovalbumin (blocking buffer) for $30 \mathrm{~min}$ at $37^{\circ} \mathrm{C}$. Mouse sera were serially diluted (1:10) in blocking buffer and a fixed amount of antigen (O1 Campos) was added. After $1 \mathrm{~h}$ incubation at $37^{\circ} \mathrm{C}$ with shaking, the virusantibody mixtures were transferred to the blocked plates, and incubated for $1 \mathrm{~h}$ at $37^{\circ} \mathrm{C}$. An optimal dilution of guinea pig $\alpha$-FMDV O1 Campos serum diluted in PBS/2\% normal bovine serum $2 \%$ normal rabbit serum was added for detection, followed by $1 \mathrm{~h}$ incubation at $37^{\circ} \mathrm{C}$. Plates were washed and peroxidase-conjugated anti-guinea pig IgG serum diluted in the same buffer was added, followed by $1 \mathrm{~h}$ incubation at $37^{\circ} \mathrm{C}$. O-phenylendiamine $/ \mathrm{H}_{2} \mathrm{O}_{2}$ was used as chromogen/peroxidase substrate and absorbance at $490 \mathrm{~nm}\left(\mathrm{~A}_{490}\right)$ was measured in a MR 5000 microplate reader. Adequate positive and negative controls were included in each test. Six control sera of known titres (reference sera of

This article is protected by copyright. All rights reserved 
high, medium and low titres) were assayed simultaneously as internal standards in each ELISA plate. Two negative control sera (unvaccinated animals) were tested. Eight wells were used for antigen concentration control (100\% reactivity) and two wells were used as reaction blanks without virus antigen and without serum. Antibody titres were expressed as the reciprocal $\log _{10}$ of serum dilutions that showed $50 \%$ of the absorbance recorded in the antigen control wells (OD 50\%).

\section{- LpELISA Repeatability}

Repeatability was expressed as the coefficient of variation of FMDV antibodies titres of the positive control sera (weak, medium and high) obtained in the assays carried out during the first year of use in the laboratory. The control sera were assayed in duplicates in every ELISA, and the mean of both replicates was required to fall within an established range of titres for the plate to be considered valid (Table 1).

- Total FMDV-specific antibodies in cattle

The assay was described by Robiolo et al. (1995). The results in cattle were provided by SENASA. Four sample dilutions (from 1:32 to 1:2048) were incubated overnight at $4{ }^{\circ} \mathrm{C}$ with a pre-titrated dose of FMDV O1 Campos in a saline buffer liquid phase. The mixtures were then incubated for $1 \mathrm{~h}$ at $37^{\circ} \mathrm{C}$ on wells coated with FMDV O1 Campos specific rabbit polyclonal antibody. After a washing step, a second incubation was performed with a saturating concentration of a pool of specific monoclonal antibodies (MAbs) against the $\mathrm{O} 1 \mathrm{Campos}$ strain. Goat anti-mouse IgG conjugated to horseradish peroxidase (Jackson InmunoResearch, USA) was added, and color development was obtained after addition of the substrate/chromophore mixture. The optical density (OD) or $\mathrm{A}_{490}$ readings were measured using an automatic microplate reader (Bio-Rad, Hercules, CA). Ab titers were expressed as the reciprocal $\log _{10}$ of serum dilutions giving $50 \%$ of the absorbance recorded in the antigen control wells $\left(\mathrm{A}_{49050 \%}\right)$. Calculations and validation of each plate were performed using proprietary software (Robiolo et al., unpublished). For validation of each 1pELISA plate, the following performance criteria were applied. Mean antibody titres for each vaccinated group were calculated and expected percentages of protection (EPP) determined from logistic regression curves previously established between antibody titres and protection against challenge (Maradei et al., 2008). $\mathrm{Ab}$ titres were calculated as the reciprocal $\log _{10}$ of serum dilutions that showed $50 \%$ of the absorbance

This article is protected by copyright. All rights reserved 
recorded in the antigen control wells. For vaccine approval, a cut-off for O1 Campos FMDV strain was set at an antibody titre of 2.1 (which corresponds to an EPP of 75\%).

\section{- $\quad \operatorname{IgG} 1$ and IgG2b Ab against FMDV in mice}

Immulon II plates were coated at $4^{\circ} \mathrm{C}$ overnight $(\mathrm{ON})$ with anti FMDV rabbit anti serum in carbonatebicarbonate $\mathrm{pH} 9.6$ buffer. After three washing steps, iFMDV was added at an optimal dilution in PBST. Plates were incubated at $37^{\circ} \mathrm{C}$ for $30 \mathrm{~min}$ and then blocked with polyvinylpyrrolidone blocking solution $(0.5 \mathrm{M} \mathrm{NaCl} ; 0.01 \mathrm{M}$ phosphate buffer; 0.05\% Tween-20; $1 \mathrm{mM}$ EDTA; 1\% polyvinylpyrrolidone $30-40 \mathrm{~K}, \mathrm{pH} 7.2)$ at $37^{\circ} \mathrm{C}$ for $45 \mathrm{~min}$. Serum samples (1:150) were added to the plates and incubated for $2 \mathrm{~h}$ at room temperature, followed by washing. Biotin-conjugated $\alpha$-mouse isotype (Caltag) was then added and incubation followed for $1 \mathrm{~h}$ at room temperature. After washing, plates were first incubated with HRP-conjugated streptavidin for $1 \mathrm{~h}$ at room temperature and then with OPD- $\mathrm{H}_{2} \mathrm{O}_{2}$, used as peroxidase substrate. $\mathrm{A}_{490}$ was recorded in a MR 5000 microplate reader (Labsystems). Positive and negative control serum samples were included in every plate.

\section{- Avidity ELISA in mice}

An ELISA-based antibody avidity assay was performed incorporating a urea elution step, as previously described (Perciani et al., 2007; Romanutti et al., 2013). The avidity of each serum was evaluated through its ability to be displaced from the plates by urea. Briefly, 96 well plates $\left(\right.$ MICROLON ${ }^{2}$, Greiner Bio-One) were coated with $\alpha$-FMDV rabbit serum in carbonate-bicarbonate pH 9.6 buffer. After three washing steps, iFMDV was added at an optimal dilution in PBST. Plates were incubated at $37^{\circ} \mathrm{C}$ for $30 \mathrm{~min}$, blocked, and then serum samples were added in a single dilution (1:50). Plates were washed twice with PBST and subsequently washed with different urea concentration (1 M to $7 \mathrm{M}$ ) in PBS (Promega, USA). FMDV-specific antibodies were detected using HRP-labelled $\alpha$-mouse IgG conjugate (Jackson Laboratories) and o-phenylenediamine- $\mathrm{H}_{2} \mathrm{O}_{2}$ as peroxidase substrate. Absorbance was recorded at $490 \mathrm{~nm}$. Mean Absorbance values of samples and controls were corrected by subtracting the mean blank $\mathrm{A}_{490}$ values (cOD). The avidity index (AI) was calculated as the percentage of residual activity of the sera relative to the $\mathrm{A}_{490}$ of the untreated (not washed with urea) sample: $\mathrm{AI}=\left(\mathrm{A}_{490}\right.$ of sample with urea/ $\mathrm{A}_{490}$ of sample without urea $) \times 100$. The

This article is protected by copyright. All rights reserved 
cut-off value was fixed at $\mathrm{A}_{490}=0.1$ (mean $\mathrm{A}_{490}$ value of 25 negative samples $+2 \mathrm{SD}$ ). Only untreated samples (PBS) with an $\mathrm{A}_{490}$ value over 0.5 were considered to calculate the AI.

Statistical studies

Statistical analyses were performed to establish the correlation between the mouse model and cattle data, including:

a) Construction of the logistic prediction model of protection: Logistic regression was used following the methodology recommended by Hosmer and Lemeshow (2000). Simple regressions for each predictor variable were analysed, selecting those variables associated with p-values lower than 0.25 to incorporate them into a multiple regression model. The model was selected considering the Akaike criterion (the smallest AIC) and the area under the ROC curve. The goodness of fit of the model was tested by the Hosmer-Lemeshow test (Hosmer and Lemeshow, 2000; Agresti, 2006).

b) Concordance of protection in mice and cattle: Two-way tables were generated to evaluate the concordance between the criteria in cattle and mice. Level of concordance was assessed using the Kappa index and its asymptotic SE, unilateral p-value and 95\% confidence interval (Altman, 1991).

Biosecurity measures

Manipulation of live virus for the experimental reproduction of the disease was performed under strict biosecurity standards in Box BSL3A in INTA. The live virus manipulation for murine tests (Quattrocchi et al. (2011) was carried out in the INTA BSL-4 OIE laboratory.

This article is protected by copyright. All rights reserved 


\section{RESULTS}

Adjustments for the development of a mouse model

\section{- Standarization of the Liquid phase ELISA}

In order to evaluate $\mathrm{Ab}$ levels against FMDV $\mathrm{O} 1 \mathrm{C}$ in sera of vaccinated mice, an lpELISA was developed. Control sera with weak, medium and high FMDV Ab levels were evaluated, different parameters were adjusted and the repeatability of the test was assessed.

Using control sera with different levels of Abs against FMDV, the variance components were calculated. As seen in Table 1, in medium and high control sera, the variance components $(\%$ total mean) associated with the observer were higher than those associated with repeatability (assay and repetition), while in the weak control sera the variance components associated with these parameters were similar.

Statistical analysis addressed the calculation of the variance components attributable to operators (observer), duplicated (assays) and repetitions. In all cases, the percentage of variation relative to the mean (\% total mean) was acceptably low and always below 5\% for the high and weak controls. For the medium control, it was $6.69 \%$, i.e. below the $10 \%$ recommended by the OIE (2008).

Therefore, once standardized, the lpELISA was used to evaluate the humoral responses induced in mice by FMD vaccines.

\section{- Kinetics of viremia after viral challenge}

With the aim of selecting the amount of virus needed for the viral challenge in mice, evaluation of the minimum dose of infection as reported by Borca et al. (1984) and Fernández et al. (1986) was readjusted due to modifications in the viremia testing techniques. Groups of 5 or 10 naïve mice were ip inoculated with different FMDV infective doses and viremia was measured $24 \mathrm{~h}$ post-inoculation.

The percentages of animals with positive viremia after inoculation of $10^{1.5}, 10^{2.5}, 10^{3.5}, 10^{4.5}$ or $10^{5.5}$ $\mathrm{TCID}_{50} / \mathrm{ml}$ of FMDV were $0,40,70,100$ and 100\%, respectively (Figure 2A). A dose of $10^{4.5}$ $\mathrm{TCID}_{50} / \mathrm{ml}$ was selected for all subsequent mice viral challenges.

On the other hand, when mice were injected with $10^{4.5} \mathrm{TCID}_{50} / \mathrm{ml}$ of FMDV, viremia kinetics showed that the maximum amount of virus in mice blood was detected at $24 \mathrm{~h}$ after viral challenge. The virus was eliminated from the blood $72 \mathrm{~h}$ post challenge (hpc) (Figure 2B). Hence, $24 \mathrm{hpc}$ was the time selected for the bleeding of animals after viral challenge.

This article is protected by copyright. All rights reserved 
- Ability of the mouse model to detect different doses of inactivated FMDV in vaccines

In order to evaluate the ability of mice to immunologically respond to vaccines containing different amounts of inactivated FMDV, as a result of modifications in viremia detection and serological tests performed, vaccines were formulated with $0.0125,0.05,0.1,0.5,1$, and $2 \mu \mathrm{g}$ inactivated FMDV per vaccine dose, using oil as adjuvant. Animals were ip vaccinated and, at $21 \mathrm{dpv}$, an exploratory bleeding and a viral challenge with the chosen concentration of active virus $\left(10^{4.5} \mathrm{TCID}_{50} / \mathrm{ml}\right)$ were performed. When protection was evaluated at $24 \mathrm{hpc}$ (Figure 3A), vaccines containing 0.0125 and $0.05 \mu \mathrm{g} /$ dose of inactivated FMDV protected 20 and $70 \%$ of mice, respectively. Vaccines with 0.1 , $0.5,1$ and $2 \mu \mathrm{g} /$ dose of inactivated FMDV induced protection in $100 \%$ of the mice. The placebo vaccine (virus-free, adjuvant only) did not protect against viral challenge. Therefore, at $21 \mathrm{dpv}$, Abs against FMDV levels increased when the amount of virus in the vaccines formulation increased (Figure 3B). Protection against FMDV and antibody levels were dependent on the amount of virus in the formulation.

Evaluation of FMDV vaccines in a mouse model and in cattle

Once 1pELISA and viral challenge parameters were established for the mouse model, 39 commercial and experimental vaccines were evaluated. Each vaccine was inoculated in cattle and mice and $\mathrm{Ab}$ levels were evaluated by lpELISA. In mice, all vaccines were also evaluated by viral challenge, while in cattle, only 16 of these vaccines were tested using viral challenge (PPG).

\section{- Vaccine classification criteria by lpELISA}

In order to explore associations between $\alpha$-FMDV Ab titres, as determined by lpELISA, in cattle and mice, concordance analysis was carried out for approved and rejected commercial vaccines.

The EPP for FMDV O1 Campos strain according to SENASA (Resolution $N^{\circ} 111 / 2010$ ) was calculated by comparing antibody lpELISA titres from vaccinated cattle sera collected at $60 \mathrm{dpv}$ with results from PPG at 90 dpv (Maradei et al., 2008).

In cattle, vaccines that induced an average $\alpha-F M D V A b$ titre equal to or higher than 2.11 were considered protective (approved), while vaccines with Abs $\alpha$-FMDV titres lower than 2.11 were considered rejected as indicated by Argentine Animal Health Service regulations (SENASA, 2010).

This article is protected by copyright. All rights reserved 
Protection in vaccinated mice was estimated using the average of $\alpha$-FMDV Ab titres at $21 \mathrm{dpv}$. This sampling time point represented the plateau of FMDV Ab response to vaccination, and represents the earliest time point of high discrimination capacity (data not shown).

After a concordance analysis with antibody levels of sera from vaccinated cattle and mice, the same cut-off value (2.11) was adopted for $\alpha$-FMDV Ab titres in mice, since it was the best discriminating value to distinguish between approved and rejected vaccines (data not shown).

Table 2A shows vaccine classification criteria by lpELISA and the association between $\alpha$-FMDV Ab titres in cattle and mice higher and lower than the cut-off value and the corresponding predicted protection (approved) or non-protection (rejected). Twenty-six out of 39 tested vaccines were approved by both methods while 9 out of 39 were rejected by both methods, 4 were approved by cattle testing but rejected by mice testing (false negative results for the mouse model). The concordance between both lpELISA in cattle and mice was 90\%, associated with a Kappa index of 0.75 (good concordance). Kappa values vary between 0 (non-concordance) and 1 (full concordance) representing degrees of concordance that exclude random events (Cohen, 1960; Fleiss et al., 1969). A Chi square value of 23.4 and a p-value $<0.0001$ were calculated by Fisher's exact test for the results obtained after the classification of the 39 vaccines.

\section{- Vaccine classification criteria by protection after viral challenge}

A vaccine classification criterion was established in mice based on protection after FMDV challenge. To set a cut-off value of protection in mice with good correlation with the PPG test in cattle, different levels of protection in vaccinated mice after viral challenge were studied. Protection of $85 \%$ of mice was the cut-off value that best discriminated between vaccines approved and rejected by SENASA regulations (data not shown) i.e., it could be established that a vaccine that induced protection in $85 \%$ of mice would induce protection in at least $75 \%$ of cattle (approved).

A two-way table (Table 2B) was assembled with the PPG data of cattle and challenged mice. Using cut-off values of $75 \%$ for PPG in cattle and $85 \%$ protection in mice, eight out of 16 vaccines tested were approved by both methods, 6 out of 16 were rejected by both methods, and 2 were approved by PPG but rejected by protection in mice (false negative results). The concordance between both methods was $88 \%$, associated with a Kappa index of 0.75 (good concordance). A Chi square value of

This article is protected by copyright. All rights reserved 
9.6 and a p-value of 0.007 were calculated by Fisher's exact test for the results obtained after the classification of the 16 vaccines.

- Misclassifications in vaccines based on protection and Ab levels

As a general rule, vaccines that induce greater protection in cattle or mice show Ab levels above the cut-off point $(>2.11)$, while those that do not induce good protection show lower levels of Abs. In order to evaluate the performance of the vaccines used in this report, two-way tables were assembled with the data of protection and Ab levels in both cattle and mice.

As shown in Table 2C with the data of both, PPG and anti FMDV Abs in cattle (EPP) using a 75\% cut-off value, the concordance between both methods (PPG and lpELISA) was 88\%, associated with a Kappa index of 0.71 (good concordance). Ten out of 16 vaccines were approved by both methods, 4 out of 16 were rejected by both methods, and 2 were approved by Abs but rejected by PPG (false positive results).

Table 2D shows the comparison between the results of protection in challenged mice and $\alpha$-FMDV Abs in mice (cut-off 85\%). The concordance between both methods (PPG and 1pELISA) was $81 \%$, associated with a Kappa index of 0.62 (moderate concordance). Eight out of 16 vaccines were approved and 5 out of 16 rejected by both methods, while 3 were approved by Abs but rejected by PPG (false-positive results).

These false-positive results could generate the introduction of non-protective vaccines with a significant health consequence. For this reason, other immunological parameters that participate in the protection against FMDV in addition to antibody levels were studied in mice in order to develop a mouse model to avoid these misclassifications.

\section{- Other immunological parameters to improve vaccine quality prediction}

Parameters reported to be related to protection against FMDV were evaluated in sera of mice vaccinated with 25 different vaccines, including total Ab titres against FMDV as well as IgA, IgG1, IgG2a, IgG2b IgG3 isotype titres against the virus, and avidity index (Lavoria et al., 2012; Pérez Filgueira et al., 1995; Romanutti et al., 2013; Cubillos et al., 2008). The results were contrasted with the protection or non-protection induced by each vaccine.

Notably, the $\operatorname{IgG} 2 \mathrm{~b} / \mathrm{IgG} 1$ ratio discriminated between protected and unprotected animals. By evaluating the attributable fraction, it was possible to calculate that if the relationship between $\mathrm{Ab}$

This article is protected by copyright. All rights reserved 
titres (IgG2b/IgG1) was higher than 1, the mouse had a 90\% probability of being protected (data not shown).

\section{- Development and performance of an Avidity test for mouse $\alpha-F M D V A b s$}

An ELISA to measure Avidity Index of murine antibodies against FMDV was developed to evaluate if this parameter could be used to estimate protection.

In a first step, different concentrations of urea were applied to separate bound immunoglobulins in positive and negative control sera. The urea concentration selected was $5 \mathrm{M}$, because it did not compromise the Avidity Index positive control (Figure 4A).

Repeatability of the avidity test was assessed using FMDV positive and negative serum controls, in sixteen independent assays, using different batches of reagents. Positive and negative control sera were obtained from pools of sera from vaccinated mice with commercial FMDV vaccines (21 dpv) previously evaluated by lpELISA and viral protection test. The selected negative sera came from nonprotected vaccinated animals. Results are shown in Figure 4B. Coefficients of variation for positive control samples were below 5\%.

Subsequently, sera of vaccinated mice with the different 25 FMDV vaccines were analysed by the Avidity ELISA. Results are shown in Figure 4C. In general, vaccines that induced better protection, showed higher Avidity Indexes. In some cases, if a FMDV vaccine induced Abs with a relatively high Avidity Index average, but with a great dispersion in the individual data, it showed low protection upon viral challenge.

\section{Construction of a protection prediction model}

A mathematical model that included an optimal subset of explanatory variables to predict vaccine protection was designed using logistic regressions (Agresti, 2006). The potential predictive variables used were: $\alpha$-FMDV Ab titre by lpELISA, $\alpha$-FMDV IgG2b titre, $\alpha$-FMDV IgG1 titre, IgG2b/IgG1 ratio, Avidity Index, $\alpha$-FMDV IgA (continuous variables) and protection or non-protection induced (dichotomous variable) of vaccinated mice. A total of 309 mice were vaccinated (16 mice per vaccine) of which 250 (80\%) were protected and 59 (20\%) unprotected after viral challenge.

\section{- Logistic Regression}


In Table 3, simple logistic regressions for each variable were analysed. Variables with p-values $<0.25$ from simple logistic regressions were incorporated into multiple regression models (Table 4). Only $\alpha$ FMDV IgG1 titres were excluded ( $\mathrm{p}$-value $=0.43$ ).

As shown in Table 4A, in multiple logistic regression model 1 , Ab titre by lpELISA, IgG2b titre, IgG2b/IgG1 Ratio, Avidity Index and IgA titre were included. Although the value of the Akaike criterion (AIC) was 248.01 and the area under the ROC curve was 0.80 , a second model was designed (multiple logistic regression model 2) using only those variables with $\mathrm{p}$ values lower than 0.05 from model 1 , in order to reduce the number of determinations and generate a more parsimonious system. Model 2 included as variables Ab titre by lpELISA, IgG2b/IgG1 Ratio and Avidity Index (Table 4B), while IgG2b titre (model 1: $\mathrm{p}$-value $=0.15)$ and IgA titre (model 1 : $\mathrm{p}$-value $=0.49)$ were excluded as variables. This model was the optimum final protection prediction model, and presented good predictive capacity and good data fit (Adjustment measures: AIC 248.14; ROC 0.80) (Figure 5).

\section{- Evaluation of the optimum logistic prediction model}

The individual data of each vaccinated mouse with each evaluated vaccine were introduced in this optimum protection prediction model. Analysis was performed for 16 vaccines for which the complete data were available, using cut-off values of $85 \%$ for mice and $75 \%$ for PPG (Table 5). Eight out of 16 vaccines were approved by PPG and estimated protection in mice, 6 were rejected by both methods, and 2 were rejected by the estimated protection in mice but approved by PPG (false negative results). However, no vaccine was approved by estimated protection in mice and rejected by PPG. It means that no false positive results were obtained. The concordance between the mouse model and protection in cattle by PPG was $88 \%$, associated with a kappa index of 0.75 .

This article is protected by copyright. All rights reserved 


\section{DISCUSSION}

FMD is one of the most devastating viral diseases that affect wild and domestic ungulates, causing significant economic losses (Alexandersen et al., 2003).

Potency testing is defined as the activity of a biological product, determined by a test method conducted on the final formulation, as described and approved by regulatory agencies in each country (Hendriksen, 1999; Taffs, 2001). Potency testing of vaccine batches is part of the control tests conducted on the final product to confirm consistency of manufacturing and to ensure batch-to-batch quality (Mc Vey, 2003).

In Argentina, potency tests of FMD vaccines are regulated by SENASA. The tests conducted in calves are painful, expensive and time-consuming. Thus, they are not adequate to be routinely used for vaccine batch release, especially in countries that have the "FMDV free with vaccination" status. In such regions, finding FMDV-seronegative bovines is becoming increasingly difficult.

Multivalent (O1/Campos, C3/Indaial, A/Arg/01, A24/Cruzeiro) commercial vaccine testing is performed nowadays by PPG challenge only for registration of new products or in the case of the introduction of a new strain in an already existing vaccine. In multivalent FMD vaccines, usually sanitary authorities test the potency of vaccine strains by serology and PPG. The same criterion is applied for regular commercial vaccine series after the registration process is completed, for which only sporadic in vivo tests are randomly performed (Maradei et al., 2008).

As FMDV is considered an exotic virus in many countries, its manipulation requires a high security laboratory, with protection against viral escapes. Also, the handling of animals in these tests is expensive, complex and causes animal suffering. On the other hand, sometimes, cattle selected for trials show good clinical condition, but subclinical pathologies that might interfere with the immune response and affect the outcome of a vaccine efficacy experiment in the natural host cannot be discarded.

This article is protected by copyright. All rights reserved 
Therefore, it is desirable to adhere to the international consensus for Reducing, Replacing and Refining the use of animals in order to obtain economical, useful and effective systems for the control of veterinary biologics, according to good animal welfare practices. Within this framework, the present study was aimed to determine the necessary measurements to perform the tests in a mouse model and avoid the manipulation of active FMDV.

The use of serologic tests, represents a convenient alternative method to evaluate batch-to-batch vaccine potency (Parreño et al., 2010). Several authors have studied different serological tests involving humoral immunity parameters in order to partially replace PPG tests (Brito et al., 2014; Capozzo et al., 1997; Maradei et al., 2008; Lavoria et al., 2012), however, these authors also propose that serum from vaccinated cattle continue to be used for different determinations. This is also expensive, since seronegative cattle from sometimes distant locations are still needed for these tests. Although significant progress has been made in using in vitro tests to evaluate antigen quality parameters, models to measure veterinary vaccine potency are still based on immunization/challenge assays in the natural host or laboratory animals (Parreño et al., 2010).

Animal models for the study of FMD are based on the use of species that are susceptible to the infection but only under experimental conditions, such as mice, guinea pigs and rabbits (Alexandersen and Mowat, 2005). The guinea pig is the best model for studying the pathogenesis of FMDV since the course of the disease is similar to that in natural hosts. As such, it has been used for the production of antisera that are subsequently used for diagnostic tests (Ferris and Donaldson, 2016). However, the lack of reagents to carry out the experiment limits the use of guinea pigs. In addition, the fact that they are not inbred animals makes it difficult to repeat the tests.

In this report, BALB/c mice were selected because naturally they are FMDV seronegative and they have a uniform genetic background. Also, the possibility of using genetically modified mice opens great opportunities for studying many different aspects of the immune response to the virus.

The mouse model has been and continues to be used in numerous studies to evaluate the efficacy of new-generation vaccines against FMD (Lee et al., 2016; Borca et al., 1984; Berinstein et al., 1993; Shi et al., 2007; Rodriguez et al., 2009; García Nuñez et al., 2009; Langellotti et al., 2012; Mignaqui et al., 2013; Romanutti et al., 2013; Quattrocchi et al., 2013; Molin Capeti et al., 2013).

This article is protected by copyright. All rights reserved 
The FMDV Ab response in mice showed a dose-dependent pattern to the viral antigen dose (Figure $3 \mathrm{~A})$. Under the conditions used, the minimum dose of antigen capable to induce a detectable $\mathrm{Ab}$ response (detection limit or minimum immunogenicity dose) was in the order of 0.0125 micrograms/dose of inactivated FMDV in oil formulation, measured by ELISA and viral challenge. The sampling time point for the mouse model was $21 \mathrm{dpv}$ representing the plateau of FMDV Ab response to vaccination with a FMDV inactivated vaccine, and represents the earliest time point of high discrimination capacity. For cattle, the sampling time point was $60 \mathrm{dpv}$ in agreement with national regulations.

Dus Santos et al. (2000) used the mouse model to compare the efficacy of vaccines in cattle and mice and obtained the same results in both species; six vaccines against FMDV O strain were evaluated in mice and cattle. They also compared different methods for the evaluation of vaccine efficacy in mice. From this comparison, it was determined that lpELISA yielded the best correlations with both Abs and protection data from the bovine model. LpELISA is an economic, applicable and simple methodology. Furthermore, it does not require the use of infective virus.

On the basis of that report, the determination of cut-off, which is one of the steps in the development of a mouse model to generate classification criteria, as well as the verification of its predictive ability on the target species were established. After performing concordance analysis, cut-off points for both the viral challenge and the lpELISA in mice were determined. The cut-off points to classify a vaccine as protective (approved) were 2.11 for mouse antibody titres and $85 \%$ of protection after challenge for mice assays.

The agreement in the classification of vaccine potency between mouse and cattle, based on these cutoff values was very good for lpELISA (Concordance 90\% Kappa 0.75 Table 2A) and FMDV challenge of mice (Concordance 88\% Kappa 0.75, Table 2B), indicating that the mouse model represents a very effective tool to predict vaccine immunogenicity in bovines.

However, we found false-positive results in the concordance analysis for vaccine classification conducted to evaluate the agreement between the lpELISA and protection against FMDV in the same species (mice or cattle). The classification of 2 vaccines by lpELISA as "approved" by cattle, were classified as "rejected" by PPG (Table 2C).

This article is protected by copyright. All rights reserved 
On the other hand, 3 vaccines were misclassified by lpELISA as "approved" by mice; however, were classified as "rejected" by challenged mice (Table 2D).

These misclassifications may constitute an economical harm for the vaccine manufacturer if only IpELISA is considered.

In this regard, the use of the other techniques for vaccine classification is proposed as an optimal method to reduce misclassifications, which does not involve the use of infective FMDV for development, and analyses them in a statistical model.

Logistic regression analysis to construct a predictive model of protection for mice was used. Parameters included in the optimal model were Abs titres by lpELISA (used in cattle to predict the possibility of a vaccine to induce protection) and other variables, such as Avidity Index and $\mathrm{IgG} 2 \mathrm{~b} / \mathrm{IgG} 1$ ratio.

Avidity Index determines the total strength of the FMDV-antibody complex. A high avidity index could carry out a more efficient elimination of the virus. This is the case of vaccines that induce high percentages of protection in cattle, but the Ab titres measured by 1pELISA do not exceed the established cut-off point $(>2,11)$ (Lavoria et al., 2012).

Immunoglobulin isotypes may play different roles in the immune response against FMDV. The $\mathrm{IgG} 2 \mathrm{~b} / \mathrm{IgG} 1$ ratio was selected because the predominance of the $\mathrm{IgG} 2 \mathrm{~b}$ isotype in sera of vaccinated mice has been associated with protection against viral challenge, therefore, higher levels of IgG2b should be able to generate a protective response in mice. In agreement with Pérez Filgueira et al. (1995) and Lavoria et al. (2012), a differential induction of isotypes in animals could help to differentiate between protected and unprotected animals.

Using the model of three variables developed in the study at hand, it was possible to predict the vaccine quality, discriminating between protected and unprotected animals at $21 \mathrm{dpv}$, without the need of using infective FMDV.

Akaike (1998) proposed a selection criterion that measures the "fit" of a given model. On the other hand, the ROC curve constitutes a statistical method to determine the diagnostic accuracy of the model, and is used to evaluate the capacity of diagnostic discrimination of the tests, i.e., their ability to differentiate between protected and non-protected animals. The mouse model presented a ROC curve with a value of 0.80 , indicating good discrimination.

This article is protected by copyright. All rights reserved 
These results allowed us to calculate the concordance between the efficacy of the vaccines by the logistic model (mouse model) and the actual efficacy obtained in cattle by the PPG test.

When an analysis with a two-way table was applied, it was clear that according to the mouse model (cut-off of $85 \%$ ) there were no vaccines rejected by PPG. Two vaccines were approved by PPG with an estimated mice status of "rejected". However, no vaccines rejected by PPG were considered "approved" by the mouse model (Table 5).

Despite two misclassifications presented by the estimated protection in the mouse model, no vaccines rejected by PPG were classified as "approved" using this model. Concordance between the mouse model and PPG was $88 \%$ with a Kappa index of 0.75 (good concordance).

Therefore, it is possible to avoid using infective virus to perform protection prediction and only measure Ab levels (lpELISA), isotype ratios and Avidity Index. This only requires inactivated virus, which could even be replaced by recombinant empty capsids in the future.

The model presents a good correlation with PPG tests and represents a major advance for the replacement of cattle in potency tests.

This is the first time that this model is presented with statistically conclusive methods, which can be used to evaluate the vaccine quality against the O1 Campos strain.

From the obtained results we conclude that the developed mouse model is a reliable tool to estimate batch-to-batch vaccine potency, avoiding the problem of finding FMDV seronegative bovines, reducing the variability that can be found in bovines and significantly reducing the cost and duration of the test. The model is also ethically compliant with the Refinement, Reduction and Replacement principle in the use of animals, that can also take part in the new consistency approach (Taffs, 2001; Hendriksen, 2009; Halder et al., 2002).

Reliability of the mouse model to evaluate the potency of FMD vaccines as well as its ease of adaptability to many different virus serotypes could lead in the near future to the complete replacement of the viral challenge, allowing the elimination of the massive use of in vivo challenge tests for regular vaccine testing and avoiding the use of infective virus for this purpose.

From these results, the mouse model is presented as a possible predictor of the behaviour of vaccines against viral challenge.

This article is protected by copyright. All rights reserved 


\section{REFERENCES}

Agresti A. An Introduction to Categorical Data Analysis: Second Edition. 2006. doi:10.1002/0470114754.

Akaike H. Information Theory and an Extension of the Maximum Likelihood Principle, 1998. doi:10.1007/978-1-4612-1694-0_15.

Alexandersen S, Mowat N. Foot-and-Mouth Disease: Host Range and Pathogenesis. Foot-and-Mouth Dis. Virus, 2005. doi:10.1007/3-540-27109-0_2.

Alexandersen S, Zhang Z, Donaldson AI, Garland AJM. The pathogenesis and diagnosis of foot-andmouth disease. J Comp Pathol 2003. doi:10.1016/S0021-9975(03)00041-0.

Alonso A, Gomes MPD, Martins MA, Sondahl MS. Detection of foot-and-mouth disease virus infection-associated antigen antibodies: comparison of the enzyme-linked immunosorbent assay and agar gel immunodiffusion tests. Prev Vet Med 1990. doi:10.1016/0167-5877(90)90069-T.

Altman DG. Statistics in medical journals: Developments in the 1980s. Stat Med 1991. doi:10.1002/sim.4780101206.

Berinstein A, Pérez Filgueira M, Schudel A, Zamorano P, Borca M, Sadir A. Avridine and LPS from Brucella ovis: Effect on the memory induced by foot-and-mouth disease virus vaccination in mice. Vaccine 1993. doi:10.1016/0264-410X(93)90098-I.

Berinstein A, Piatti P, Gaggino OP, Schudel AA, Sadir AM. Enhancement of the immune response elicited with foot-and-mouth disease virus vaccines by an extract of the Mycobacterium sp. wall. Vaccine 1991. doi:10.1016/0264-410X (91)90008-T.

Borca M V., Fernández FM, Sadir AM, Schudel AA. Reconstitution of immunosuppressed mice with mononuclear cells from donors sensitized to foot-and- mouth disease virus (FMDV). Vet Microbiol 1984. doi:10.1016/0378-1135(84)90051-8.

This article is protected by copyright. All rights reserved 
Brito BP, Perez AM, Capozzo AV. Accuracy of traditional and novel serology tests for predicting cross-protection in foot-and-mouth disease vaccinated cattle. Vaccine 2014. doi:10.1016/j.vaccine.2013.12.007.

Capozzo AVE, Periolo OH, Robiolo B, Seki C, La Torre JL, Grigera PR. Total and isotype humoral responses in cattle vaccinated with foot and mouth disease virus (FMDV) immunogen produced either in bovine tongue tissue or in BHK-21 cell suspension cultures. Vaccine 1997. doi:10.1016/S0264410X(96)00284-8.

Cohen J. A Coefficient of Agreement for Nominal Scales. Educ Psychol Meas 1960. doi:10.1177/001316446002000104.

Cubillos C, de la Torre BG, Jakab A, Clementi G, Borras E, Barcena J, et al. Enhanced Mucosal Immunoglobulin A Response and Solid Protection against Foot-and-Mouth Disease Virus Challenge Induced by a Novel Dendrimeric Peptide. J Virol 2008. doi:10.1128/jvi.00401-08.

Dus Santos MJ, Wigdorovitz A, Maradei E, Periolo O, Smitsaart E, Borca M V., et al. A Comparison of Methods for Measuring the Antibody Response in Mice and Cattle following Vaccination against Food and Mouth Disease. Vet Res Commun 2000. doi:10.1023/A:1006450900739.

Fernández FM, Borca M V., Sadir AM, Fondevila N, Mayo J, Schudel AA. Foot-and-mouth disease virus (FMDV) experimental infection: Susceptibility and immune response of adult mice. Vet Microbiol 1986. doi:10.1016/0378-1135(86)90037-4.

Ferris NP, Donaldson AI. Serological response of guinea pigs to inactivated 146S antigens of foot and mouth disease virus after single or repeated inoculations. Rev Sci Tech l'OIE 2016. doi:10.20506/rst.3.3.173.

Filho YLV, Astudillo V, Gomes I, Fernández G, Rozas CEE, Ravison JA, et al. Potency control of foot-and-mouth disease vaccine in cattle. Comparison of the 50\% protective dose and the protection against generalization. Vaccine 1993. doi:10.1016/0264-410X(93)90171-S.

This article is protected by copyright. All rights reserved 
Fleiss JL, Cohen J, Everitt BS. Large sample standard errors of kappa and weighted kappa. Psychol Bull 1969. doi:10.1037/h0028106.

Galdo Novo S, Malirat V, Maradei ED, Pedemonte AR, Espinoza AM, Smitsaart E, et al. Efficacy of a high quality $\mathrm{O} 1$ /Campos foot-and-mouth disease vaccine upon challenge with a heterologous Korean O Mya98 lineage virus in pigs. Vaccine 2018. doi:10.1016/j.vaccine.2018.02.015.

García-Nuñez S, König G, Berinstein A, Carrillo E. Differences in the virulence of two strains of Foot-and-Mouth Disease Virus Serotype A with the same spatiotemporal distribution. Virus Res 2010. doi:10.1016/j.virusres.2009.10.013.

Halder M, Hendriksen C, Cussler K, Balls M. ECVAM's contributions to the implementation of the Three Rs in the production and quality control of biologicals. ATLA Altern to Lab Anim 2002.

Hamblin C, Kitching RP, Donaldson AI, Crowther JR, Barnett ITR. Enzyme-linked immunosorbent assay (ELISA) for the detection of antibodies against foot-and-mouth disease virus: III. Evaluation of antibodies after infection and vaccination. Epidemiol Infect 1987. doi:10.1017/S0950268800066590.

Hendriksen CF. Validation of tests methods in the quality control of biologicals. Dev Biol Stand 1999.

Hendriksen CFM. Replacement reduction and refinement alternatives to animal use in vaccine potency measurement. Expert Rev Vaccines 2009. doi:10.1586/14760584.8.3.313.

Hosmer DW, Lemeshow S. Applied logistic regression. Appl. Logist. Regres., 2000. doi:10.1080/00401706.1992.10485291.

Langellotti C, Quattrocchi V, Alvarez C, Ostrowski M, Gnazzo V, Zamorano P, et al. Foot-and-mouth disease virus causes a decrease in spleen dendritic cells and the early release of IFN- $\alpha$ in the plasma of mice. Differences between infectious and inactivated virus. Antiviral Res 2012. doi:10.1016/j.antiviral.2012.02.009.

This article is protected by copyright. All rights reserved 
Lavoria M ángeles, Di-Giacomo S, Bucafusco D, Franco-Mahecha OL, Pérez-Filgueira DM, Capozzo AV. Avidity and subtyping of specific antibodies applied to the indirect assessment of heterologous protection against Foot-and-Mouth Disease Virus in cattle. Vaccine 2012. doi:10.1016/j.vaccine.2012.09.011.

Lee SY, Ko MK, Lee KN, Choi JH, You SH, Pyo HM, et al. Application of mouse model for effective evaluation of foot-and-mouth disease vaccine. Vaccine 2016. doi:10.1016/j.vaccine.2016.06.008.

López OJ, Sadir AM, Borca M V., Fernández FM, Braun M, Schudel AA. Immune Response to Footand-Mouth Disease Virus in an Experimental Murine Model II. Basis of Persistent Antibody Reaction. Vet Immunol Immunopathol 1990. doi:10.1016/0165-2427(90)90002-A.

Maradei E, La Torre J, Robiolo B, Esteves J, Seki C, Pedemonte A, et al. Updating of the correlation between 1pELISA titers and protection from virus challenge for the assessment of the potency of polyvalent aphtovirus vaccines in Argentina. Vaccine 2008. doi:10.1016/j.vaccine.2008.09.033.

McVey DS, Galvin JE, Olson SC. A review of the effectiveness of vaccine potency control testing. Int J Parasitol 2003. doi:10.1016/S0020-7519(03)00067-5.

Mignaqui AC, Ruiz V, Perret S, St-Laurent G, Singh Chahal P, Transfiguracion J, et al. Transient Gene Expression in Serum-Free Suspension-Growing Mammalian Cells for the Production of Footand-Mouth Disease Virus Empty Capsids. PLoS One 2013. doi:10.1371/journal.pone.0072800.

Molin-Capeti KC, Sepulveda L, Terra F, Torres-Pioli MF, Costa-Casagrande T, França SC, et al. A proposal for an alternative quality control test procedure for inactivated vaccines against food-andmouth disease virus. Vaccine 2013. doi:10.1016/j.vaccine.2012.12.001.

OIE. World Organisation for Animal Health. Manual of Diagnostic Tests and Vaccines for Terrestrial Animals. World Organ Anim Heal 2008.

This article is protected by copyright. All rights reserved 
OIE. Foot and Mouth Disease Foot and Mouth Disease. Terr Man 2009. doi:10.1177/146642401303400206.

Ostrowski M, Vermeulen M, Zabal O, Zamorano PI, Sadir AM, Geffner JR, et al. The Early Protective Thymus-Independent Antibody Response to Foot-and-Mouth Disease Virus Is Mediated by Splenic CD9+ B Lymphocytes. J Virol 2007. doi:10.1128/jvi.00677-07.

PANAFTOSA. Catálogo de publicaciones 1952-1993. Rio de Janeiro: 1994.

Parreño V, López MV, Rodriguez D, Vena MM, Izuel M, Filippi J, et al. Development and statistical validation of a guinea pig model for vaccine potency testing against Infectious Bovine Rhinothracheitis (IBR) virus. Vaccine 2010. doi:10.1016/j.vaccine.2010.01.035.

Pega J, Bucafusco D, Di Giacomo S, Schammas JM, Malacari D, Capozzo A V., et al. Early Adaptive Immune Responses in the Respiratory Tract of Foot-and-Mouth Disease Virus-Infected Cattle. J Virol 2013. doi:10.1128/jvi.02879-12.

Perciani CT, Peixoto PS, Dias WO, Kubrusly FS, Tanizaki MM. Improved method to calculate the antibody avidity index. J Clin Lab Anal 2007. doi:10.1002/jcla.20172.

Pérez Filgueira DM, Berinstein A, Smitsaart E, Borca M V., Sadir AM. Isotype profiles induced in Balb/c mice during foot and mouth disease (FMD) virus infection or immunization with different FMD vaccine formulations. Vaccine 1995. doi:10.1016/0264-410X(95)00078-F.

Quattrocchi V, Langellotti C, Pappalardo JS, Olivera V, Di Giacomo S, van Rooijen N, et al. Role of macrophages in early protective immune responses induced by two vaccines against foot and mouth disease. Antiviral Res 2011. doi:10.1016/j.antiviral.2011.08.007.

Quattrocchi V, Molinari P, Langellotti C, Gnazzo V, Taboga O, Zamorano P. Co-inoculation of baculovirus and FMDV vaccine in mice, elicits very early protection against foot and mouth disease virus without interfering with long lasting immunity. Vaccine 2013. doi:10.1016/j.vaccine.2013.03.067.

This article is protected by copyright. All rights reserved 
Quattrocchi V, Pappalardo JS, Langellotti C, Smitsaart E, Fondevila N, Zamorano P. Early protection against foot-and-mouth disease virus in cattle using an inactivated vaccine formulated with Montanide ESSAI IMS D 12802 VG PR adjuvant. Vaccine 2014. doi:10.1016/j.vaccine.2014.02.061.

Robiolo B, Grigera PR, Periolo OH, Seki C, Bianchi T, Maradei E, et al. Assessment of foot and mouth disease vaccine potency by liquid-phase blocking ELISA: a proposal for an alternative to the challenge procedure in Argentina. Vaccine 1995. doi:10.1016/0264-410X(94)00084-Z.

Rodriguez Pulido M, Sobrino F, Borrego B, Saiz M. Attenuated Foot-and-Mouth Disease Virus RNA Carrying a Deletion in the 3' Noncoding Region Can Elicit Immunity in Swine. J Virol 2009. doi:10.1128/jvi.01836-08.

Romanutti C, D'Antuono A, Palacios C, Quattrocchi V, Zamorano P, La Torre J, et al. Evaluation of the immune response elicited by vaccination with viral vectors encoding FMDV capsid proteins and boosted with inactivated virus. Vet Microbiol 2013. doi:10.1016/j.vetmic.2013.04.017.

SENASA. Resolución SENASA 111/2010. Argentina: 2010.

SENASA. Resolución SENASA 609. Buenos Aires, Argentina: 2017.

Shi XJ, Wang B, Wang M. Immune enhancing effects of recombinant bovine IL-18 on foot-andmouth disease vaccination in mice model. Vaccine 2007. doi:10.1016/j.vaccine.2006.10.017.

Sobrino F, Sáiz M, Jiménez-Clavero MA, Núñez JI, Rosas MF, Baranowski E, et al. Foot-and-mouth disease virus: A long known virus, but a current threat. Vet Res 2001. doi:10.1051/vetres:2001106.

Soria I, Quattrocchi V, Langellotti C, Gammella M, Digiacomo S, Garcia de la Torre B, et al. Dendrimeric peptides can confer protection against foot-and-mouth disease virus in cattle. PLoS One 2017. doi:10.1371/journal.pone.0185184.

Taffs RE. Potency Tests of Combination Vaccines. Clin Infect Dis 2001. doi:10.1086/322574.

This article is protected by copyright. All rights reserved 
van Bekkum JG. Correlation between serum antibody level and protection against challenge with FMD-virus. Eur. Comm. Control FMD, Sess. Res. Gr. standing Tech. Comm., 1969.

\section{FIGURE LEGENDS}

Figure 1: Experimental design in mice and cattle. Animals were vaccinated at day 0. Challenge tests were carried out at 21 and $90 \mathrm{dpv}$, respectively. For viremia, mice were bled at $22 \mathrm{dpv}$. Cattle were clinical checked 7 days post viral challenge.

Figure 2: Selection of the virus dose for the viral challenge and measurement of viremia at different hours post challenge (hpc) in BALB/c mice. A) Selection of infective dose of FMDV. Each bar represents the percentage of mice with detectable viremia with respect to the total number of infected animals $24 \mathrm{~h}$ after inoculation of different FMDV doses. B) Viremia curve at different hpc: viral titres $\left(\mathrm{TCID}_{50} / \mathrm{ml}\right)$ reached in blood at 24,48 and $72 \mathrm{hpc}$ in mice inoculated with $10^{4.5} \mathrm{TCID}_{50} / \mathrm{ml}$ of FMDV. Each point represents the mean $\pm \mathrm{SD}$ of the viral titres reached by mice in the different groups.

Figure 3: Protection and $\mathrm{Ab}$ response of mice vaccinated with different amounts of inactive FMDV (iFMDV) O1 Campos strain. A) Percentage of animals protected after vaccination and challenge at $21 \mathrm{dpv}$. Each bar represents the number of mice protected/number of mice challenged x 100. B) $\alpha$-FMDV Ab titres by lpELISA at $21 \mathrm{dpv}$ with different doses of iFMDV O1 Campos, formulated with commercial adjuvant. Points represent the $\mathrm{Ab}$ titre of each mouse. The horizontal lines indicate the average obtained for each experimental group.

Figure 4: A) Avidity Index of positive $(n=4)$ and negative $(n=4)$ mouse sera with different urea concentrations. Points represent means \pm SD. B) Avidity Index of positive and negative control sera in 16 different assays. Mean, SD and coefficient of variation (CV) calculations were carried out. Treatments with urea were performed after incubation of sera in 5M urea. C) Avidity Index of experimental and commercial vaccines. Vaccines are arranged according to the highest to the lowest percentage of animals protected by each formulation. The Avidity Index was calculated as the $A_{490}$ of the urea-treated well/ $A_{490}$ of the untreated well (PBS) x 100.

Figure 5: Optimum logistic prediction model includes Ab titres by lpELISA, IgG2b/IgG1 ratio, and Avidity Index. Goodness of fit was calculated according to Hosmer-Lemeshow; *p-value above 0.05 indicates that the data conform to the model.

This article is protected by copyright. All rights reserved 
Table 1: LpELISA Repeatability: Analysis of the Components of variance, $\%$ Total Variance and \% Total Mean for titres of control mouse sera (Observer, Assay and Repetition). S2: Variance calculated as 1) $\mathrm{S}_{\mathrm{i}}^{2} / \mathrm{S}_{\text {total }}^{2}$ or 2) $\mathrm{S}_{\mathrm{i}}^{2} /$ Total Mean

Sera with Abs against FMDV

$\begin{array}{ccccc}\text { Total } & \text { Observer } & \text { Assay } & \text { Repetition } & \text { Total Mean } \\ & (n=2) & (n=2) & (n=9) & \text { Ab titres }\end{array}$

$\begin{array}{llllll}\text { Variance }^{(\mathrm{S} 2)} & 0.0125 & 0.0031 & 0.0062 & 0.0032 & 1.66\end{array}$

Weak Control \% Total Variance ${ }^{(1)}$

$24.8 \quad 49.6 \quad 25.6$

$\%$ Total Mean ${ }^{(2)}$

$3.35 \quad 4.74 \quad 3.41$

Medium

Variance $^{(\mathrm{S} 2)}$

0.0262

0.0181

0.0052

3.41

Control

$\%$ Total Variance ${ }^{(1)}$

69.1

19.8

0.0029

2.01

Control Total Mean ${ }^{(2)}$

0.0436

6.69

3.59

11.1

Variance $^{(\mathrm{S} 2)}$

High Control

$\%$ Total Variance
$\%$ Total Mean
$(2)$

0.0263

0.0044

2.68

2.01

$\begin{array}{lll}60.3 & 10.1 & 29.6 \\ 4.46 & 1.82 & 3.12\end{array}$

0.0129

3.64

$\%$ Total Mean ${ }^{(2)}$

4.46


Table 2: Classification of FMD vaccines. Two-way tables were constructed to classify vaccines as "approved" or "rejected", according to the results obtained by A) Comparison of vaccines between vaccinated mice and vaccinated cattle by using mean group $\alpha$-FMDV Ab titres by lpELISA at 21 and $60 \mathrm{dpv}$ respectively. Cut-off determination: score of 39 vaccines by using 2.11 as cut-off value for vaccine approval in cattle and mice. B) Comparison of mouse challenge tests at $21 \mathrm{dpv}$ and protection in cattle according to the Podal Generalization (PPG) test at 90 dpv (cut-off $85 \%$ and $75 \%$ of protection, respectively). C) Comparison of vaccines in vaccinated cattle using the PPG test at $90 \mathrm{dpv}$ (cut-off 75\%) and mean group $\alpha$-FMDV Ab titres by lpELISA at $60 \mathrm{dpv}$ (cut-off 2.11). D) Comparison of vaccines in vaccinated mice using viral challenge at $21 \mathrm{dpv}$ (cut-off $85 \%$ ) and mean group $\alpha$-FMDV Ab titres by lpELISA at $21 \mathrm{dpv}$ (cut-off 2.11).

A

Bovine $\alpha$-FMDV

Abs

\begin{tabular}{ccccc} 
& & & & \\
\cline { 3 - 5 } & & Approved & Rejected & Total \\
\hline Murine $\alpha$ - & Approved & 26 & 0 & 26 \\
FMDV Abs & Rejected & 4 & 9 & 13 \\
& Total & 30 & 9 & 39
\end{tabular}

Concordance $90 \%$

Kappa 0.75

C

PPG

Approved Rejected Total Approved

Abs $\alpha$ -

FMDV cattle

10

Total

0

10

$\begin{array}{cc}2 & 12 \\ 4 & 4 \\ 6 & 16 \\ \text { Concordance } & 88 \%\end{array}$

Kappa 0.71
B

\begin{tabular}{ccccc} 
& & & \\
& & & & \\
\cline { 3 - 5 } Cpproved & Rejected & Total \\
\hline \multirow{2}{*}{$\begin{array}{c}\text { Challenged } \\
\text { mice }\end{array}$} & Approved & 8 & 0 & 8 \\
& Rejected & 2 & 6 & 8 \\
& Total & 10 & 6 & 16 \\
& & \multicolumn{3}{c}{ Concordance 88\% } \\
& & \multicolumn{3}{r}{ Kappa 0.75 }
\end{tabular}

D

\begin{tabular}{ccccc} 
& & \multicolumn{3}{c}{ Challenged mice } \\
\cline { 3 - 5 } & & Approved & Rejected & Total \\
\hline \multirow{2}{*}{ Abs $\alpha-$} & Approved & 8 & 3 & 11 \\
FMDV mice & Rejected & 0 & 5 & 5 \\
& Total & 8 & 8 & 16 \\
& & \multicolumn{3}{c}{ Concordance 81\% } \\
& \multicolumn{4}{c}{ Kappa 0.62 }
\end{tabular}


Table 3: Variables analysed by Simple Logistic Regressions according to the protection results in each mouse, independently of the vaccine used.

Variable Odds ratio $(95 \% \mathrm{CI}) \quad$ p-value

\begin{tabular}{llc}
\hline$\alpha$-FMDV Ab titres by lpELISA & $2.77(1.72-4.44)$ & $<0.0001$ \\
$\alpha$-FMDV lgG2b titres & $1.60(1.00-2.56)$ & 0.0515 \\
$\alpha$-FMDV lgG1 titres & $0.84(0.55-1.30)$ & 0.4340 \\
IgG2b/IgG1 Ratio & $3.90(1.21-12.57)$ & 0.0225 \\
Avidity Index & $1.07(1.05-1.10)$ & $<0.0001$ \\
& & \\
$\alpha$-FMDV IgA Abs $\left(\mathrm{A}_{490}\right)$ & $8.90(0.54-147.13)$ & 0.1267 \\
\hline
\end{tabular}

This article is protected by copyright. All rights reserved 
Table 4: Multiple Logistic Regressions of variables with Simple Logistic Regression p-value <0.25.

Model selection according to Akaike's criterion (AIC) and Area under the ROC curve (ROC). A)

Model 1: Multiple Logistic Regression of $\alpha$-FMDV Ab titres by lpELISA, $\alpha$-FMDV IgG2b titres, $\operatorname{IgG} 2 \mathrm{~b} / \operatorname{IgG} 1$ Ratio, Avidity Index and $\alpha$-FMDV $\operatorname{IgA} \mathrm{Abs}\left(\mathrm{A}_{490}\right)$, according to the protection results of each mouse (Adjustment measures: AIC 248.01; ROC 0.80). B) Model 2: Multiple Logistic Regression of variables with p-value $<0.05$ in Model 1; IgA Abs and $\alpha$-FMDV IgG2b titres were excluded (Adjustment measures: AIC 248.14; ROC 0.80).

A

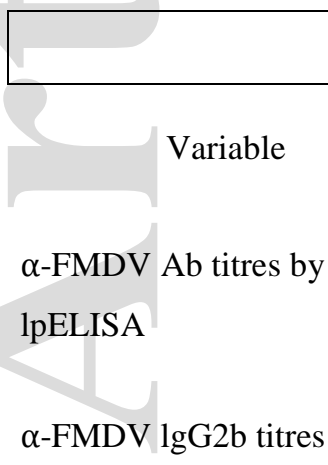

$\operatorname{IgG} 2 \mathrm{~b} / \mathrm{IgG} 1$ Ratio

Avidity Index

$\alpha$-FMDV IgA Abs $\left(\mathrm{A}_{490}\right)$

\section{Model 1}

Odds ratio $(95 \% \mathrm{CI})$

$2.13(1.27-3.59)$

$1.48(0.86-2.53)$

0.1572

$5.79(1.33-25.19)$

0.0191

$1.07(1.05-1.10) \quad<0.0001$

$2.79(0.15-53.37)$
B

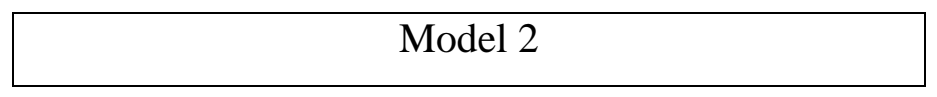

Variable

Odds ratio $(95 \% \mathrm{CI}) \quad \mathrm{p}$-value

\begin{tabular}{lll}
\hline$\alpha$-FMDVAb titres by & $2.28(1.37-3.78)$ & 0.0015 \\
lpELISA &
\end{tabular}

IgG2b/IgG1 Ratio

$6.95(1.68-28.70)$

0.0074

Avidity Index

$1.07(1.05-1.10)$

$<0.0001$ 
Table 5: Two-way table to classify vaccines $(\mathrm{n}=16)$ as "approved" or "rejected" according to the results obtained by comparison of real protections in bovines (PPG test at $90 \mathrm{dpv}$, cut-off $75 \%$ ) with estimated protected mouse (predictive model at $21 \mathrm{dpv}$, cut-off $85 \%$ ). Chi square 9.6 and p-value 0.007 were calculated by Fisher's test for the results obtained after the classification of the 16 vaccines.

\begin{tabular}{ccccc} 
& & \multicolumn{2}{c}{ PPG } & \\
\cline { 3 - 5 } & & Approved & Rejected & Total \\
\hline $\begin{array}{c}\text { Estimated } \\
\text { Protected } \\
\text { Mice }\end{array}$ & Approved & 8 & 0 & 8 \\
& Rejected & 2 & 6 & 8 \\
& Total & 10 & 6 & 16 \\
& & & \multicolumn{2}{c}{$\begin{array}{c}\text { Concordance } 88 \% \\
\text { Kappa 0.75 }\end{array}$}
\end{tabular}

This article is protected by copyright. All rights reserved 
Mice vaccination Bleeding

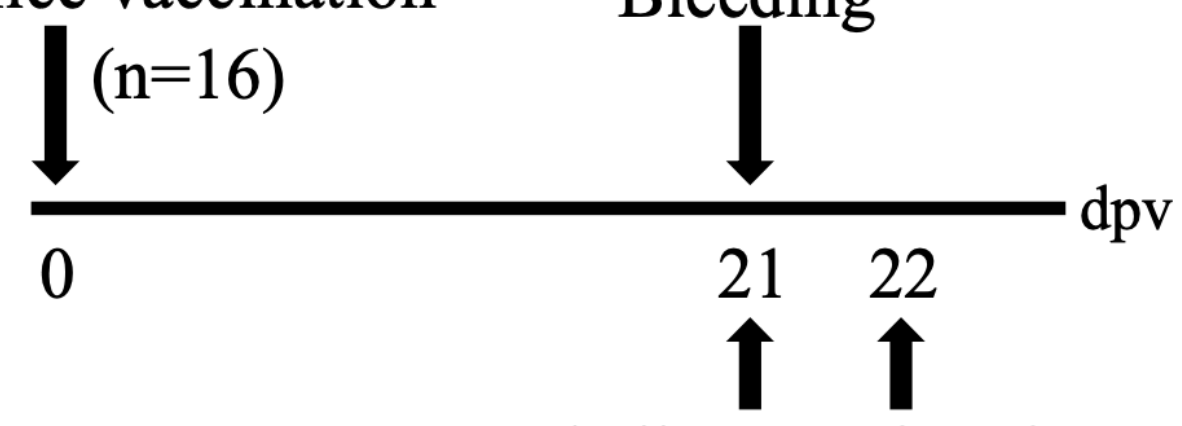

Challenge Viremia

Cattle vaccination

$(n=16)$

Bleeding Bleeding Bleeding

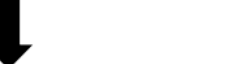

0

30

60

dpv

Challenge Clinical check 
A

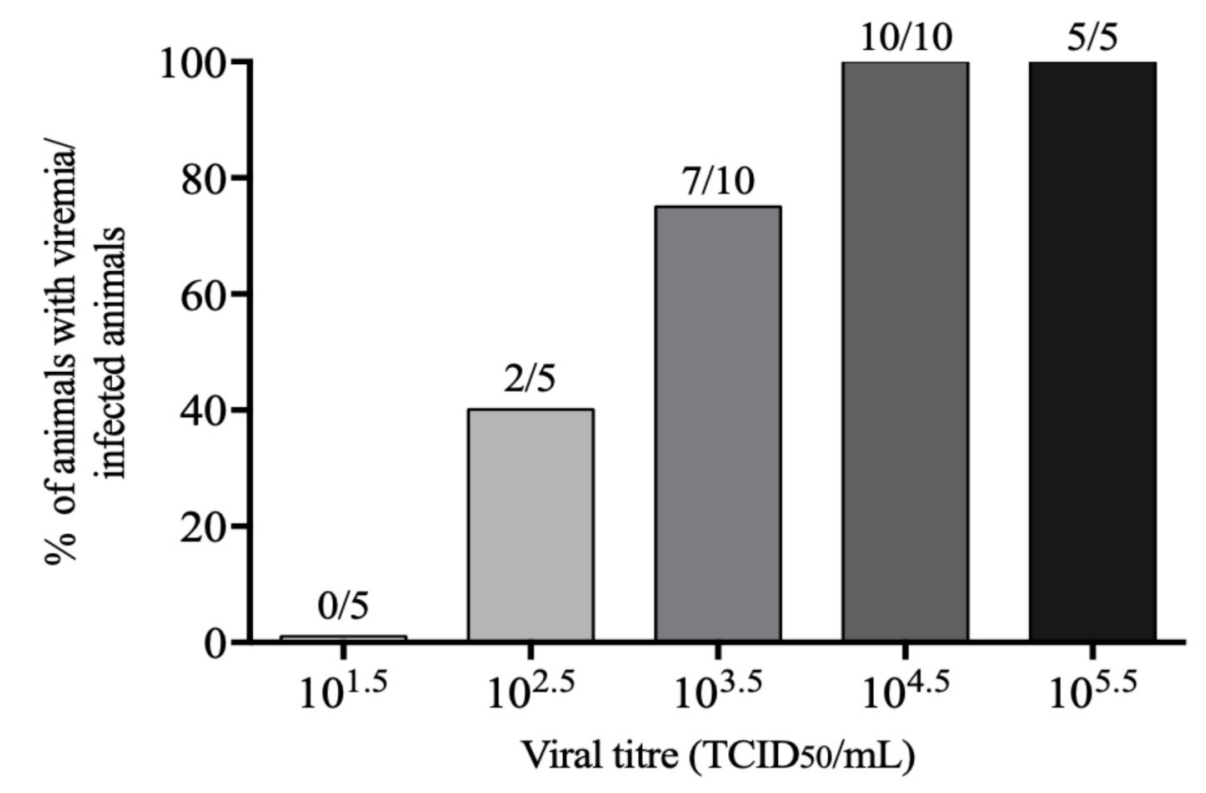

B

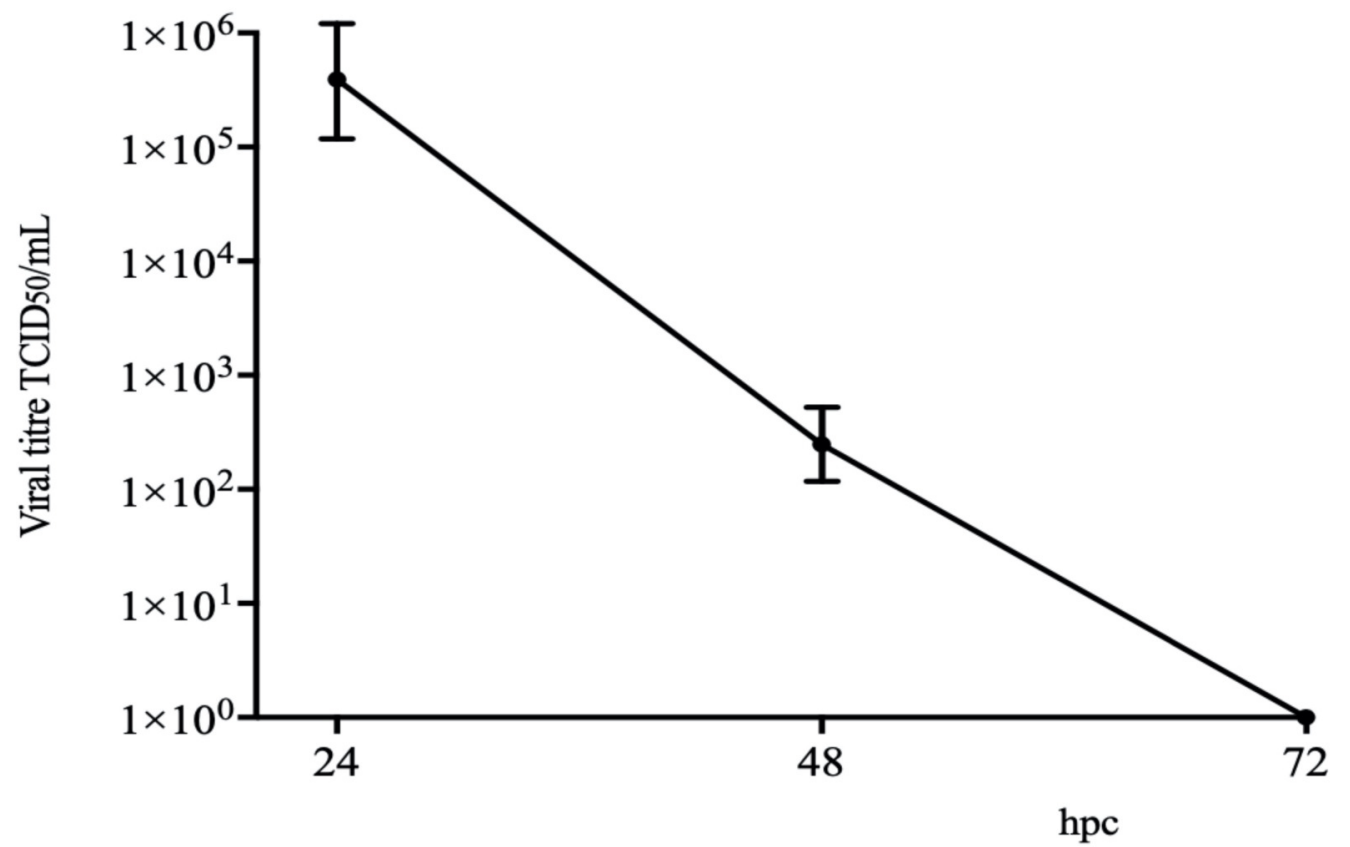


A

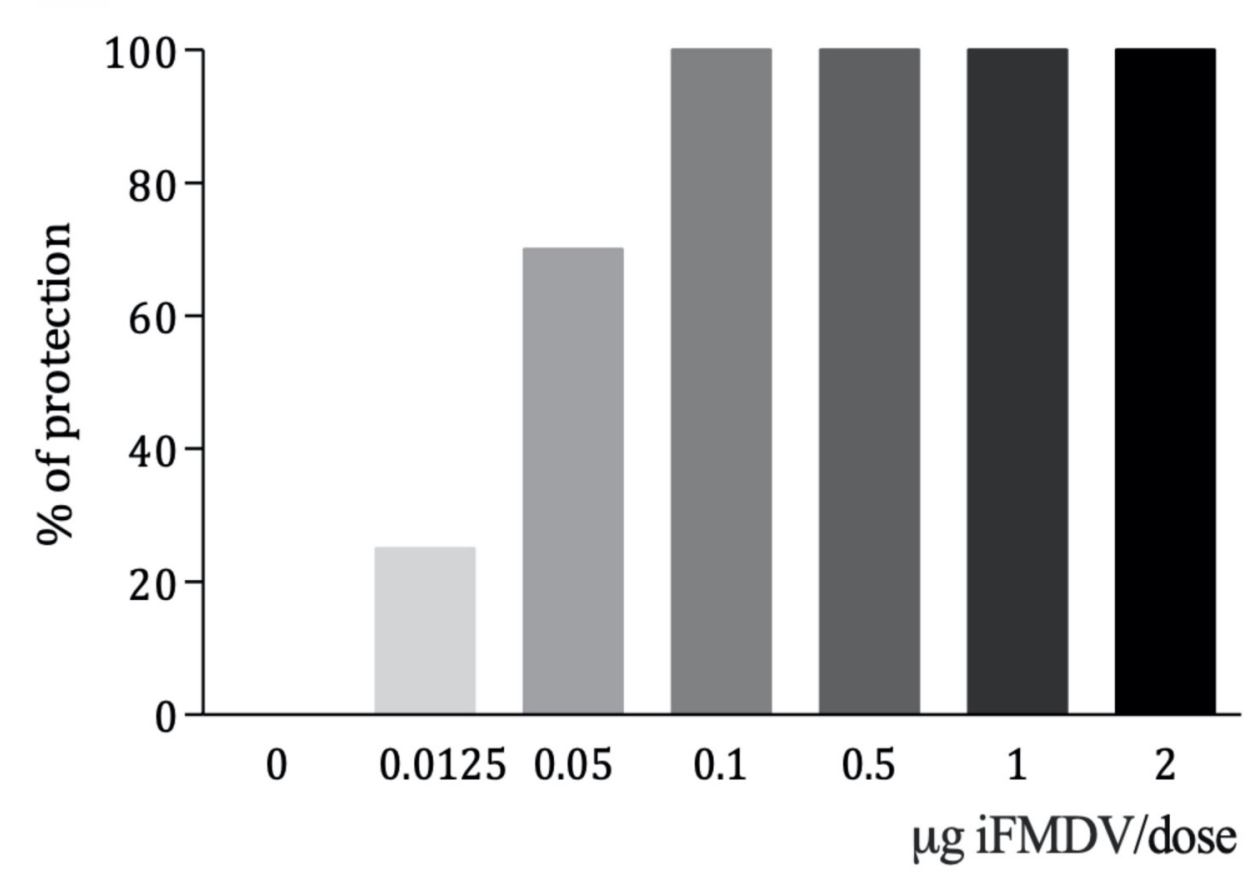

B

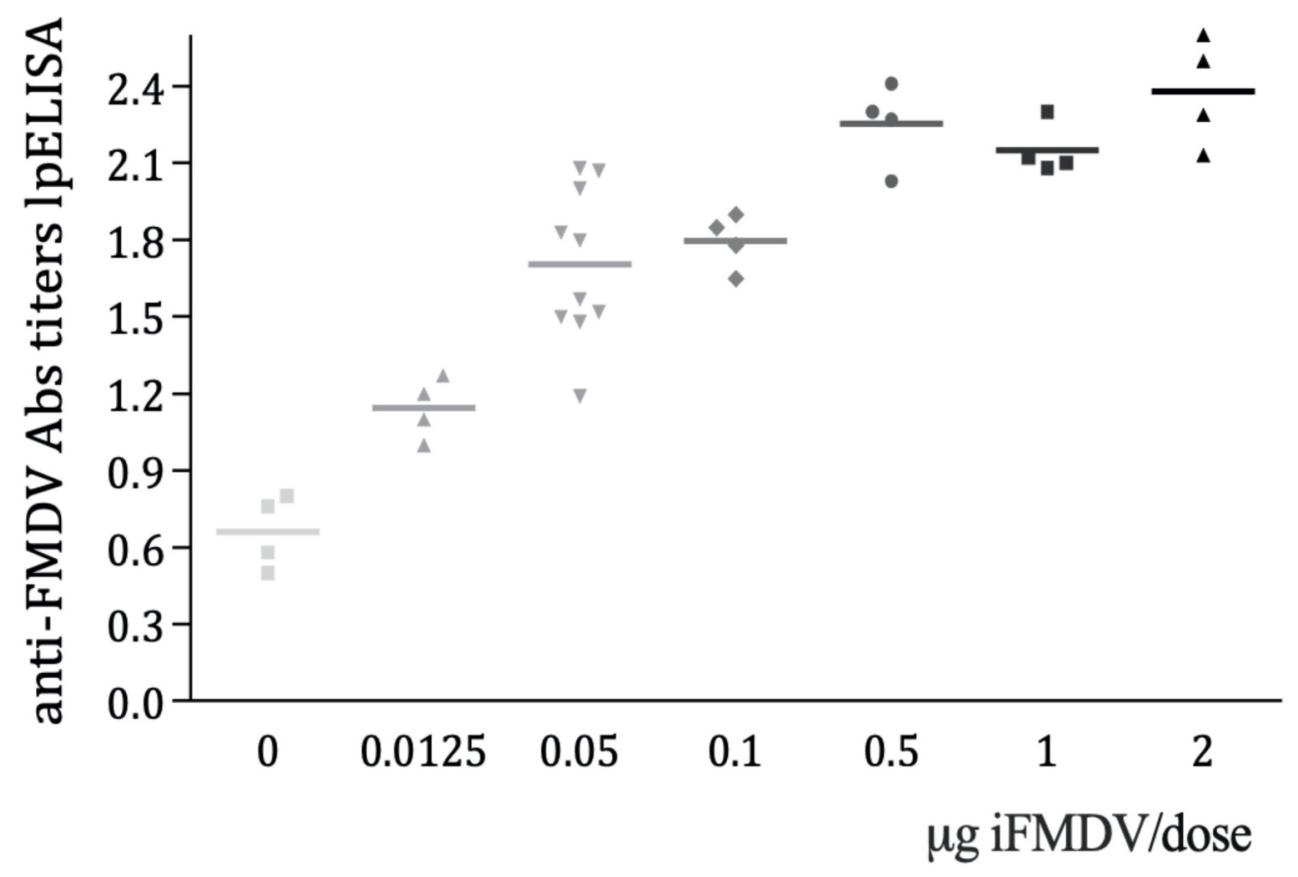


A

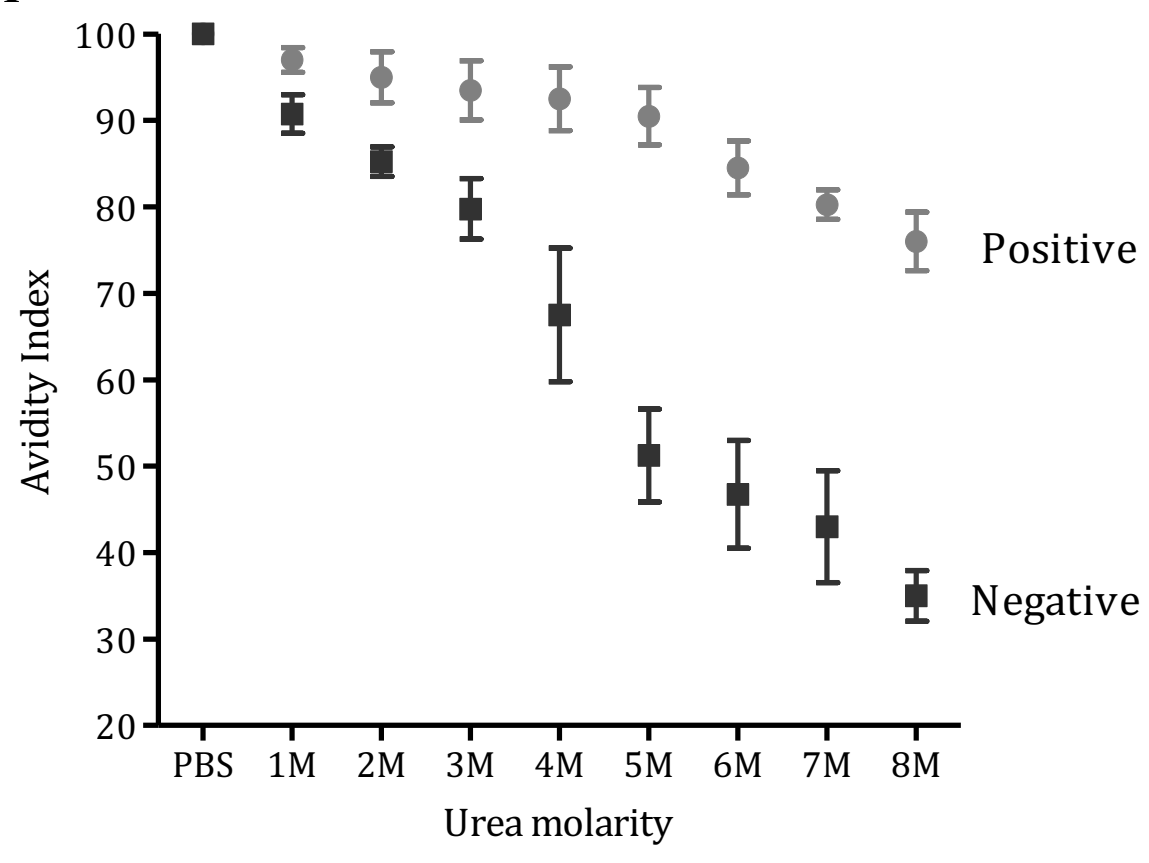

C

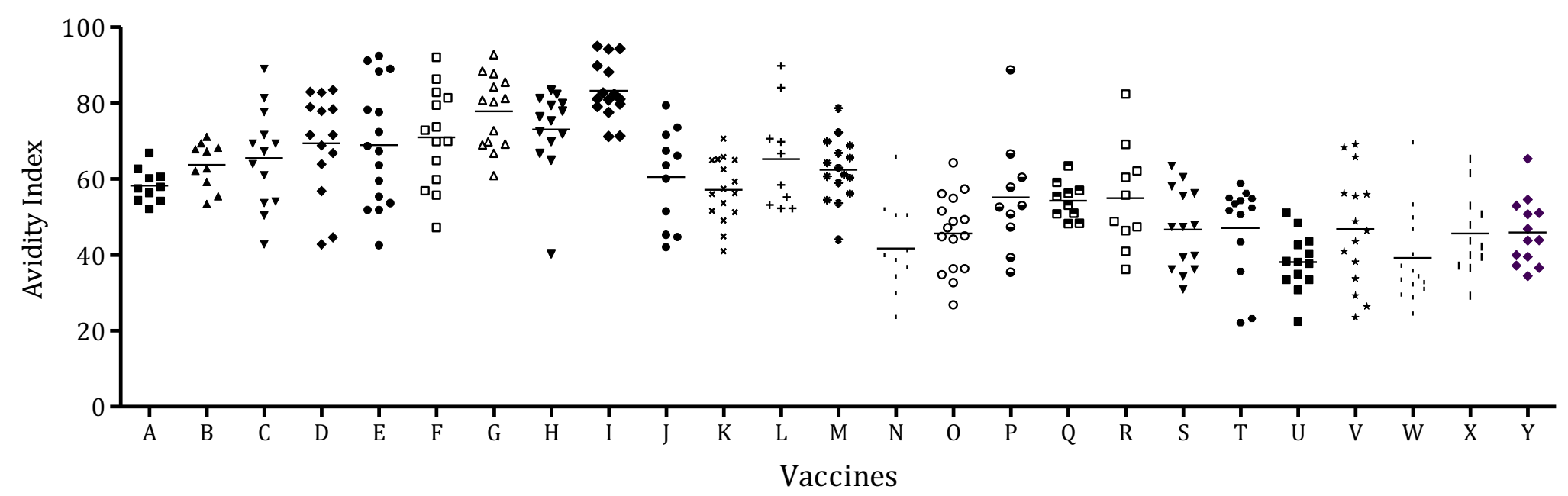

B

\begin{tabular}{ccc} 
Assay & Control + & Control - \\
\hline 1 & 91,0 & 43,0 \\
2 & 89,7 & 45,5 \\
3 & 93,8 & 50,3 \\
4 & 93,9 & 49,0 \\
5 & 88,5 & 43,8 \\
6 & 88,0 & 46,0 \\
7 & 89,1 & 49,0 \\
8 & 87,3 & 47,4 \\
9 & 86,3 & 50,5 \\
10 & 89,1 & 50,6 \\
11 & 86,8 & 46,5 \\
12 & 85,6 & 44,2 \\
13 & 86,9 & 48,2 \\
14 & 88,3 & 46,7 \\
15 & 86,4 & 47,8 \\
16 & 89,6 & 47,7 \\
Mean & 88,8 & 47,3 \\
SD & 2,5 & 2,4 \\
CV & 2,8 & 5,0
\end{tabular}




\section{Optimum logistic prediction model}

$$
\hat{\pi}=\frac{\exp \left(-5.64+0.82 A b s_{-} l p E L I S A+1.94 I g G 2 b / I g G 1+0.07 \text { Avidity }\right)}{1+\exp \left(-5.64+0.82 A b s_{-} l p E L I S A+1.94 I g G 2 b / I g G 1+0.07 \text { Avidity }\right)}
$$

Measures of adjustment of the model

$$
\mathrm{AIC}=248.14 ; \mathrm{ROC}=0.80
$$

Proof of fitness of the Hosmer-Lemeshow model

Chi-square $=2.21 \mathrm{p}$-value $=0.9741^{*}$ 